\title{
Cardiac troponins as biomarkers for cardiac disease
}

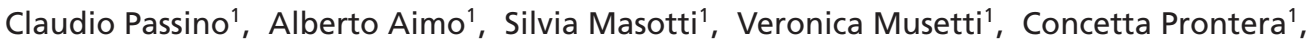 \\ Michele Emdin ${ }^{1}$ \& Aldo Clerico*,1 \\ ${ }^{1}$ Fondazione CNR Regione Toscana G Monasterio \& Scuola Superiore Sant'Anna, Pisa, Italy \\ *Author for correspondence: clerico@ftgm.it
}

“high-sensitivity methods allowed the accurate detection of cTn levels in healthy adults"

First draft submitted: 22 January 2019; Accepted for publication: 21 February 2019; Published online: 3 April 2019

Keywords: acute coronary syndrome $\bullet$ cardiac troponins $\bullet$ high sensitivity methods $\bullet$ myocardial infarction $\bullet$ quality specification • reference population • risk stratification

Cardiovascular disease (CVD) is a leading cause of death, morbidity and hospitalization worldwide [1-3]. Patient risk stratification is a crucial goal, as it informs therapy and follow-up strategies, with the ultimate goal of impacting on the natural history of the disease. Laboratory biomarkers are regarded with interest as tools for prognostic stratification [4-7]. Over the last years, more than 100 new biomarkers have been evaluated under this respect, with more than 4000 clinical studies published [4,5].

Assessing the prognostic accuracy of a novel cardiovascular biomarker is very complex [3,6,7]. According to the principles of Evidence-Based Laboratory Medicine, a biomarker should not only be an independent predictor of outcome in multiple regression models, but also influence patient management [8], which is the prerequisite for cost-efficacy $[5,8]$. As a result, very few novel laboratory biomarkers end up being recommended for risk prediction $[5,9,10]$.

Heart failure (HF) is the terminal form of many cardiac diseases [11]. Natriuretic peptides (NPs) and cardiac troponins (cTns) independently contribute to cardiovascular risk assessment because these biomarkers are involved in different pathophysiological mechanisms related to cardiac dysfunction and HF progression [11]. A large number of clinical studies demonstrated that plasma NPs and cTn are independent predictors of prognosis in HF $[2,10,12-18]$. Based on these findings, the 2017 American College of Cardiology Federation/American Heart Association/Heart Failure Society Association Guidelines confirmed that NPs and cTns are the first-line biomarkers for risk stratification in both acute and chronic HF [10].

The use of cardiac-specific biomarkers for risk prediction in the general population is controversial and was not contemplated before 2010 [19], possibly because immunoassay methods able to measure the circulating levels of cTns in the majority of apparent healthy individuals (including both adult and pediatric ages) have been introduced only recently [20-25]. Here we discuss the recent evidence that circulating levels of cTns, measured with high-sensitivity (hs) methods, may be increased even in asymptomatic individuals. We believe that an initial myocardial remodeling could account for a rise in cTn, conferring a higher risk of developing HF to these subjects.

\section{cTns as cardiovascular risk biomarkers in the general population}

Only after the year 2006, the introduction in the clinical laboratory routine of immunoassays with increased analytical sensitivity (hs-methods) allowed the detection of increased levels of cTnI and cTnT in patients with cardiac diseases other than myocardial infarction (MI), in patients with extra-cardiac diseases (renal, pulmonary and inflammatory diseases), and even in some apparently healthy subjects [15-18,25,28-33]. Furthermore, several studies [3453], including also three meta-analyses $[45,52,53]$, demonstrated that the cardiovascular risk tend to increase also in some apparently healthy individuals of both sexes; in other words, for cTn values below the 99th percentile URL, which is the cut-off value recommended by all the international guidelines for the diagnosis of MI [54-56].

Future 8 Medicine 
In particular, in 2017 Willeit et al. [53] performed a meta-analysis including 28 studies, involving 154,052 participants. The cTnI values, measured by Architect (14 studies) and Erenna (three studies) methods, were detectable in $82.6 \%$ of individuals, while those of cTnT in only 69.7\% (ECLIA method, 11 studies).

More recently, Welsh et al. [51] evaluated the distribution and association between cTnT (measured by ECLIA method), $\mathrm{CTnI}$ (measured by the Architect method) and other cardiovascular risk factors in a large general population cohort (19,501 individuals, age range: 18-98 years). Detectable concentrations of cTnT and cTnI were found in 10,395 participants $(53.3 \%)$ and 14579 (74.8\%), respectively. Women and younger individuals were more likely to demonstrate undetectable concentrations of cTns [51]. More than $50 \%$ of women in the $\leq 50-59$ year age-groups had undetectable cTnT and $>50 \%$ of women in the $\leq 30-39$ year age-groups had undetectable cTnI [51]. There were 296 male participants (3.6\%) and 897 female participants (7.9\%) with a cTnT result above the recommended 99th percentile (15.5 and $9.0 \mathrm{ng} / \mathrm{l}$, respectively). For cTnI, 83 male participants (1.0\%) and 115 female participants (1.0\%) were above the recommended 99th percentile (34.2 and $15.6 \mathrm{ng} / \mathrm{l}$, respectively) [51]. On average, higher troponin levels were found more frequently in older individuals with higher BMI, systolic blood pressure and creatinine values, with a history of CVD or diabetes, and use of cholesterol medications [51]. A composite 10-year CVD risk score calculated in participants without prevalent CVD and $\geq 35$ years of age yielded not significantly different $(\mathrm{p}=0.34)$ positive associations with both $\mathrm{c} \operatorname{TnT}$ and $\mathrm{cTnI}[51]$.

In the North-Trøndelag Health (HUNT) study [50], authors measured TnI with the Architect hs method in a cohort of a general population, including 9005 participants [50]. The prognostic accuracy of hs-TnI, assessed by C-statistics, was significantly greater than that of the standard model, also including C-reactive protein $(0.753 \mathrm{vs}$ 0.644) [50]. It is important to note that the tertile with the highest risk showed a cut-off value of $10 \mathrm{ng} / \mathrm{l}$ for women and $12 \mathrm{ng} / \mathrm{l}$ for men, which is a cTnI value below the 99th percentile suggested by the manufacturer [50],

\section{Analytical performance, pathophysiological considerations \& clinical relevance}

The most important quality specifications concerning the 'high-sensitivity' methods for the cTn assay are related to estimation of 99th percentile URL. The 2018 Expert Opinion from the AACC and IFCC [55] recommends that high-sensitivity methods should satisfy two fundamental criteria. First, hs-methods should measure the 99th percentile URL with an imprecision (expressed as coefficient of variation, percent coefficient of variation [CV] \%) $\leq 10 \%$; second, these assays should be able to detect cTn concentration at or above the limit of detection (LoD) in at least $50 \%$ of healthy men and women.

Marjot et al. [25] recently reported that the high-sensitivity methods for $\mathrm{CTnI}$ and cTnT are able to detect cardiac injury due to necrosis of just $40 \mathrm{mg}$ of myocardium, equivalent to $0.015 \%$ of the heart, sufficient to increase serum concentrations above the 99th percentile URL. According to these data, cTn immunoassays with limit of detection less than $3 \mathrm{ng} / \mathrm{l}$ should be able to measure a cTn amount released from 6 to $8 \mathrm{mg}$ of myocardial tissue [25,26]. Accordingly, the analytical sensitivity of these high-sensitivity cTnI methods is greatly higher than the spatial resolution of the most sensitive cardiac imaging techniques [25,26]. The intra-individual variation in healthy adult subjects of cTnI, evaluated with high-sensitivity method, is on average about $8-10 \%$ [27]. Considering these data as a whole, some authors suggested that the circulating levels of cTnI, measured with high-sensitivity immunoassays, in healthy adult subjects may be considered as a reliable estimate of the physiological turnover of human myocardial tissue [26].

The 2018 fourth universal definition of myocardial infarction [56] states that: "the term myocardial injury should be used when there is evidence of elevated cTn values with at least one value above the 99th percentile upper reference limit." Myocardial injury is a prerequisite for the diagnosis of MI, but also a distinct entity [57]. Indeed, several cardiac and systemic pathologies can result in myocardial injury without infarction. These conditions should be accurately distinguished from MI [56-58].

The estimation of 99th percentile strongly depends not only on demographic and physiological variables of the reference population, but also on the analytical performances of cTn methods, and the mathematical algorithm used for calculating the 99th value [59,60]. cTnI values measured with the Architect method in an Italian reference population, including 675 healthy subjects (age range: $18-86$ years, age: $50.1 \pm 13.9$ years, 348 women and 327 men) is not normally distributed with a 99th percentile value $(28.0 \mathrm{ng} / \mathrm{l})$ that is 15.6 -fold higher than the median value $(1.8 \mathrm{ng} / \mathrm{l})$. These data confirm the results previously reported in the HUNT study for a Scandinavian general population including 3670 apparently healthy men and 4429 apparently healthy women [45].

According to Callum G Fraser [61,62], the bidirectional Z-score Reference Change Value (RCV) between two results, with its $95 \% \mathrm{CI}$, can be calculated by considering both the analytical variability of the method $\left(\mathrm{CV}_{\mathrm{A}}\right)$ and 
the intra-individual variability $\left(\mathrm{CV}_{\mathrm{I}}\right)$, using Formula 1:

$$
\mathrm{RCV}=1.96\left[2\left(\mathrm{CV}_{\mathrm{A}}^{2}+\mathrm{CV}_{\mathrm{I}}^{2}\right)\right]^{1 / 2}
$$

For example, the $\mathrm{CV}_{\mathrm{A}}$ estimated by the imprecision profile using standardized protocols [21,22], is $18.1 \%$ for a cTnI concentration of $2.0 \mathrm{ng} / \mathrm{l}$, measured with the high-sensitivity cTnI method (hs-cTnI) Architect method. Furthermore, Van der Linden et al. [27] have recently reported that the $\mathrm{CV}_{\mathrm{I}}$ of $\mathrm{cTnI}$ measured with the Architect method is about $9 \%$ in adult healthy subjects. By using these values of $\mathrm{CV}_{\mathrm{A}}$ and $\mathrm{CV}_{\mathrm{I}}$ in the Formula 1, it is possible to estimate the RCV value as $56.0 \%$ and the absolute $\Delta$ change as $1.1 \mathrm{ng} / \mathrm{l}$ for a $95 \%$ probability. This means that, for a cTnI concentration of $2.0 \mathrm{ng} / \mathrm{l}$, an increase or decrease of $1.1 \mathrm{ng} / \mathrm{l}$ should be considered significant with $95 \%$ probability. In a similar way, RCV and $\Delta$ change for the range of Architect cTnI concentrations from 2 to $40 \mathrm{ng} / \mathrm{l}$ can be calculated. These values are well in agreement with the absolute $\Delta$ changes in Architect cTnI values proposed by the 2016 ESC guidelines for the $0 / 1 \mathrm{~h}$ rule-in and rule-out algorithms for the diagnosis of non-ST segment elevation MI, considering also cTnI values below the upper reference levels [54]. When a population is considered instead of the single individual, these notions translate in the concept that increasingly cTn values reflect different degrees of cardiomyocyte renewal even when well below the 99th percentile values. It then comes as to no surprise that the cardiovascular risk in the general population seems to increase continuously and progressively from very low cTn values (for example, cTnI values of $4 \mathrm{ng} / \mathrm{l}$ for women and $6 \mathrm{ng} / \mathrm{l}$ for men in the HUNT study) [45].

From a clinical perspective, the observation of an increment in hs-cTnI levels, even of only $3-5 \mathrm{ng} / \mathrm{l}$ over some months in a patient with a suspect of cardiomyopathy should suggest an initial myocardial remodeling, ultimately culminating in symptomatic HF [10,11]. Indeed, cTnI distribution in the reference population indicate that an individual with a cTnI concentration equal to the medial value $(1.8 \mathrm{ng} / \mathrm{l})$ should increase his/her myocardial renewal of about 16 -fold in order to reach the 99th percentile value (i.e., $28.0 \mathrm{ng} / \mathrm{l}$ ).

Only very recently the introduction of high-sensitivity methods allowed the accurate detection of cTn levels in healthy adults [20-27]. Several studies [34-53] demonstrated that the cardiovascular risk progressively increases in the general population even for cTn values well below the 99th percentile, in other words, the recognized cut-off for the detection of myocardial injury and/or diagnosis of MI [56]. An early and effective treatment is needed to revert the initial myocardial remodeling and slow down HF progression $[5,11,13,26]$. High-sensitivity cTn methods enable to monitor myocardial renewal and remodeling, and to promptly identify patients at highest risk to HF development [26], possibly resulting in early diagnosis and improved prognosis.

\section{Financial \& competing interests disclosure}

The authors have no relevant affiliations or financial involvement with any organization or entity with a financial interest in or financial conflict with the subject matter or materials discussed in the manuscript. This includes employment, consultancies, honoraria, stock ownership or options, expert testimony, grants or patents received or pending, or royalties.

No writing assistance was utilized in the production of this manuscript.

\section{References}

1 Goff DC Jr, Lloyd-Jones DM, Bennett G et al. 2013 ACC/AHA guideline on the assessment of cardiovascular risk: a report of the American College of Cardiology/ American Heart Association Task Force on Practice Guidelines. J. Am. Coll. Cardiol. 63(25 Pt B), 2935-2959 (2014).

2 Piepoli MF, Hoes AW, Agewall S et al. 2016 European Guidelines on cardiovascular disease prevention in clinical practice. Eur. Heart J. 37(29), 2315-2381 (2016).

3 Khambhati J, Allard-Ratick M, Hhindsa D et al. The art of cardiovascular risk assessment. Clin. Cardiol. 41(5), 677-684 (2018).

4 Collins DRL, Tompson AC, Onakpoya IJ et al. Global cardiovascular risk assessment in the primary prevention of cardiovascular disease in adults: systematic review of systematic reviews. BMJ Open 7(3), e013650 (2017).

5 Emdin M, Vittorini S, Passino C, Clerico A. Old and new biomarkers of heart failure. Eur. J. Heart Fail. 11(4), 331-335 (2009).

6 Hlatky MA, Greenland P, Arnett DK et al. Criteria for evaluation of novel markers of cardiovascular risk: a scientific statement from the American Heart Association. Circulation 119(17), 2408-2416 (2009).

7 Wang TJ. Assessing the role of circulating, genetic and imaging biomarkers in cardiovascular risk prediction. Circulation 123(5), 551-565 (2011). 
8 Price CP, Christenson RH. The clinical question: a system for formulating answerable questions in laboratory medicine. In: Evidence-Based Laboratory Medicine - Principles, Practice, and Outcome (Second Edition). AACC Press, Washington DC, USA, 25-52 (2007).

9 Ponikowski P, Voors AA, Anker SD et al. 2016 ESC Guidelines for the diagnosis and treatment of acute and chronic heart failure: the Task Force for the diagnosis and treatment of acute and chronic heart failure of the European Society of Cardiology (ESC). Developed with the special contribution of the Heart Failure Association (HFA) of the ESC. Eur. J. Heart Fail. 18(8), 891-975 (2016).

10 Yancy CW, Jessup M, Bozkurt B et al. 2017 ACCF/AHA/HFSA focused update for the 2013 ACCF/AHA guideline for the management of heart failure: a report of the American College of Cardiology Foundation/American Heart Association Task Force on Practice Guidelines and the Heart Failure Society of America. Circulation 136(6), e137-e161 (2017).

11 Braunwald E. Heart failure. J. Am. Coll. Cardiol. Heart Fail. 1(1), 1-20 (2013).

12 Chow SL, Maisel AS, Anand I et al. Role of biomarkers for the prevention, assessment, and management of heart failure: a scientific statement from the American Heart Association. Circulation 135(22), e1054-e1091 (2017).

13 Emdin M, Passino C, Prontera C et al. Comparison of brain natriuretic peptide (BNP) and amino-terminal proBNP for early diagnosis of heart failure. Clin. Chem. 53(7), 1289-1297 (2007).

14 Swoboda PP, McDiarmid AK, Erhayiem B et al. Diabetes mellitus, microalbuminuria, and subclinical cardiac disease: identification and monitoring of individuals at risk of heart failure. J. Am. Heart Assoc. 6(7), e005539 (2017).

15 Álvarez I, Hernàndez L, García H et al. High-sensitivity troponin T assay in asymptomatic high cardiovascular risk patients. The TUSARC Registry. Rev. Esp. Cardiol. 70(4), 261-266 (2017).

16 Hasler S, Manka R, Greutmann M et al. Elevated high-sensitivity troponin T levels are associated with adverse cardiac remodelling and myocardial fibrosis in hypertrophic cardiomyopathy. Swiss Med. Wkly 146, w14285 (2016).

17 Neeland IJ, Drazner MH, Berry JD et al. Biomarkers of chronic cardiac injury and hemodynamic stress identify a malignant phenotype of left ventricular hypertrophy in the general population. J. Am. Coll. Cardiol. 61(2), 187-195 (2013).

18 Sundström J, Ingelsson E, Berglund L et al. Cardiac troponin-I and risk of heart failure: a community-based cohort study. Eur. Heart J. 30(7), 773-781 (2009).

19 Greeland P, Alpert FS, Beller GA et al. 2010 ACCF/AHA guideline for for assessment of cardiovascular risk in asymptomatic adult: a report of the American College of Cardiology Foundation/American Heart Association Task Force on Practice Guidelines. J. Am. Coll. Cardiol. 56(25), e50-e103 (2010).

20 Krintus M, Kozinski M, Boudry P et al. European multicenter analytical evaluation of the Abbott ARCHITECT STAT highly sensitive troponin I immunoassay. Clin. Chem. Lab. Med. 52(11), 1657-1665 (2014).

21 Caselli C, Cangemi G, Masotti S et al. Plasma cardiac troponin I concentrations in healthy neonates, children and adolescents measured with a highly sensitive immunoassay method: highly sensitive troponin I in pediatric age. Clin. Chim. Acta 458, 68-71 (2016).

22 Masotti S, Prontera C, Musetti V et al. Evaluation of analytical performance of a new high-sensitivity immunoassay for cardiac troponin I. Clin. Chem. Lab. Med. 56(3), 492-501 (2018).

23 Masotti S, Musetti V, Prontera C et al. Evaluation of analytical performance of a chemiluminescence enzyme immunoassay (CLEIA) for cTnI using the automated AIA-CL2400 platform. Clin. Chem. Lab. Med. 56(9), e174-e176 (2018).

24 Musetti V, Masotti S, Prontera C et al. Evaluation of the analytical performance of a new ADVIA immunoassay using the Centaur XPT platform system for the measurement of cardiac troponin I. Clin. Chem. Lab. Med. 56(9), e229-e231 (2018).

25 Marjot J, Kaier TE, Martin ED et al. Quantifying the release of biomarkers of myocardial necrosis from cardiac myocytes and intact myocardium. Clin. Chem. 63(5), 990-996 (2017).

26 Giannoni A, Giovannini S, Clerico A. Measurement of circulating concentrations of cardiac troponin I and T in healthy subjects: a tool for monitoring myocardial tissue renewal?. Clin. Chem. Lab. Med. 47(10),1167-177 (2009).

27 Van der Linden N, Hilderink JM, Cornelis T et al. Twenty-four-hour biological variation profiles of cardiac troponin I in individuals with or without chronic kidney disease. Clin. Chem. 63(10), 1655-1656 (2017).

28 Giannitsis E, Katus HA. Cardiac troponin level elevations not related to acute coronary syndromes. Nat. Rev. Cardiol. 10(11), 623-634 (2013).

29 Collinson P. The role of cardiac biomarkers in cardiovascular disease risk assessment. Curr. Opin. Cardiol. 29(4), 366-371 (2014).

30 Ahmed AN, Blonde K, Hackam D, Iansavichene A, Mrkobrada M. Prognostic significance of elevated troponin in non-cardiac hospitalized patients: a systematic review and meta-analysis. Ann. Med. 46(8), 653-663 (2014).

31 Michos ED, Wilson LM, Yeh HC et al. Prognostic value of cardiac troponin in patients with chronic kidney disease without suspected acute coronary syndrome: a systematic review and meta-analysis. Ann. Intern. Med. 161(7), 491-501 (2014).

32 Khan NA, Hemmelgarn BR, Tonelli M, Thompson CR, Levin A. Prognostic value of troponin T and I among asymptomatic patients with end-stage renal disease: a meta-analysis. Circulation 112(20), 3088-3096 (2005).

33 Lipinski MJ, Baker NC, Escárcega RO et al. Comparison of conventional and high-sensitivity troponin in patients with chest pain: a collaborative meta-analysis. Am. Heart J. 169(1), 6-16 (2015). 
34 Eggers KM, Venge P, Lindahl B, Lind L. Cardiac troponin I levels measured with a high-sensitive assay increase over time and are strong predictors of mortality in an elderly population. J. Am. Coll. Cardiol. 61(18), 1906-1913 (2013).

35 de Lemos JA, Drazner MH, Omland T et al. Association of troponin T detected with a highly sensitive assay and cardiac structure and mortality risk in the general population. JAMA 304(22), 2503-2512 (2010).

36 Hussein AA, Gottdiener JS, Bartz TM et al. Cardiomyocyte injury assessed by a highly sensitive troponin assay and sudden cardiac death in the community: the Cardiovascular Health Study. J. Am. Coll. Cardiol. 62(22), 2112-2120 (2013).

37 Eggers KM, Al-Shakarchi J, Berglund L et al. High-sensitive cardiac troponin T and its relations to cardiovascular risk factors, morbidity, and mortality in elderly men. Am. Heart J. 166(3), 541-548 (2013).

38 Oluleye OW, Folsom AR, Nambi V, Lutsey Pl, Ballantyne CM, ARIC Study Investigators. Troponin T, B-type natriuretic peptide, C-reactive protein, and cause-specific mortality. Ann. Epidemiol. 23(2), 66-73 (2013).

39 Omland T, de Lemos JA, Holmen OL et al. Impact of sex on the prognostic value of high-sensitivity cardiac troponin I in the general population: the HUNT study. Clin. Chem. 61(4), 646-656 (2015).

40 Zeller T, Tunstall-Pedoe $\mathrm{H}$, Saarela $\mathrm{O}$ et al. High population prevalence of cardiac troponin I measured by a high-sensitivity assay and cardiovascular risk estimation: the MORGAM Biomarker Project Scottish Cohort. Eur. Heart J. 35(5), 271-281 (2014).

41 Masson S, Agabiti N, Vago T et al. The fibroblast growth factor-23 and Vitamin D emerge as nontraditional risk factors and may affect cardiovascular risk. J. Intern. Med. 277(3), 318-330 (2015).

42 Neumann JT, Havulinna AS, Zeller T et al. Comparison of three troponins as predictors of future cardiovascular events: prospective esults from the FINRISK and BiomaCaRE studies. PLoS ONE 9(3), e90063 (2014).

43 Wang TJ, Wollert KC, Larson MG et al. Prognostic utility of novel biomarkers of cardiovascular stress: the Framingham Heart Study. Circulation 126(13), 1596-1604 (2012).

44 Thorsteinsdottir I, Aspelund T, Gudmundsson E et al. High-sensitivity cardiac troponin I is a strong predictor of cardiovascular events and mortality in the AGES-Reykjavik community-based cohort of older individuals. Clin. Chem. 62(4), 623-630 (2016).

45 Van der Linden N, Klinkenberg LJ, Bekers O et al. Prognostic value of basal high-sensitive cardiac troponin levels on mortality in the general population: a meta-analysis. Medicine 95(52), e5703 (2016).

46 Blankenberg S, Salomaa V, Makarova N et al. Troponin I and cardiovascular risk prediction in the general population: the BiomarCaRE consortium. Eur. Heart J. 37(30), 2428-2437 (2016).

47 Hughes MF, Ojeda F, Saarela $\mathrm{O}$ et al. Association of repeatedly measured high-sensitivity-assayed troponin I with cardiovascular disease events in a general population from the MORGAM/BiomarCaRE Study. Clin. Chem. 63(1), 334-342 (2017).

48 Zhu K, Knuiman M, Divitini M et al. High-sensitivity cardiac troponin I and risk of cardiovascular disease in an Australian population-based cohort. Heart 104(11), 895-903 (2018).

49 Zellweger MJ, Haaf P, Maraun M et al. Predictors and prognostic impact of silent coronary artery disease in asymptomatic high-risk patients with diabetes mellitus. Int. J. Cardiol 244, 37-42 (2017).

50 Sigurdardottir FD, Lynbakken MN, Holmen OL et al. Relative prognostic value of cardiac troponin I and C-reactive protein in the general population (from the North-Trøndelag Health [HUNT] Study. Am. J. Cardiol. 121(8), 949-955 (2018).

51 Welsh P, Preiss D, Shah ASV et al. Comparison between high-sensitivity cardiac troponin $\mathrm{T}$ and cardiac troponin I in a large general population cohort. Clin. Chem. 64(11), 1607-1616 (2018).

52 Sze J, Mooney J, Barzi F, Hillis GS, Chow CK. Cardiac troponin and its relationship to cardiovascular outcomes in community populations - a systematic review and meta-analysis. Heart Lung Circ. 25(3), 217-228 (2016).

53 Willeit P, Welsh P, Evans JDW et al. High-sensitivity cardiac troponin concentration and risk of first-ever cardiovascular outcomes in 154,052 participants. J. Am. Coll. Cardiol. 70(5), 558-568 (2017).

54 Roffi M, Patrono C, Collet JP et al. 2015 ESC Guidelines for the management of acute coronary syndromes in patients presenting without persistent ST-segment elevation: Task Force for the Management of Acute Coronary Syndromes in Patients Presenting without Persistent ST-Segment Elevation of the European Society of Cardiology (ESC). Eur. Heart J. 37(3), 267-315 (2016).

55 Wu AHB, Christenson RH, Greene DN et al. Clinical laboratory practice recommendations for the use of cardiac troponin in acute coronary syndrome: expert opinion from the Academy of the American Association for Clinical Chemistry and the Task Force on Clinical Applications of Cardiac Bio-Markers of the International Federation of Clinical Chemistry and Laboratory Medicine. Clin. Chem. 64(4), 645-655 (2018).

56 Thygesen K, Alpert JS, Jaffe AS et al. Fourth universal definition of myocardial infarction. J. Am. Coll. Cardiol. 72(18), 2231-2264 (2018).

57 Thygesen K. What's new in the fourth universal definition of myocardial infarction? Eur. Heart J. 39(42), 3757-3758 (2016).

58 Valentine CM, Tcheng JE, Waites T. Translating the translation. What clinicians should know about the fourth universal definition of myocardial infarction. J. Am. Coll. Cardiol. 72(21), 2668-2670 (2018).

59 Clerico A, Zaninotto M, Ripoli A et al. The 99th percentile of reference population for cTnI and cTnT assay: methodology, pathophysiology and clinical implications. Clin. Chem. Lab. Med. 55(11), 1634-1651 (2017). 
60 Sandoval Y, Apple FS. The global need to define normality: the 99th percentile value of cardiac troponin. Clin. Chem. 60(3), 455-462 (2014).

61 Fraser CG. Chapter 3. Biological Variation: From Principle to Practice. AACC Press, Washington DC, USA, 67-90 (2001).

62 Fraser CG. Reference change values. Clin. Chem. Lab. Med. 50(5), 807-812 (2011). 